http://jmscr.igmpublication.org/home/ ISSN (e)-2347-176x ISSN (p) 2455-0450 crossref DOI: https://dx.doi.org/10.18535/jmscr/v9i12.23

\title{
Dorsal Wrist Ganglion - Our Experience in its Management at Tertiary Care Centre
}

\author{
Authors \\ Dr K. Srinivasa Chakravarty M S ${ }^{1}$, Dr Eppala Tejaswi ${ }^{2 *}$, Dr Gopi Chandra Goli ${ }^{3}$ \\ ${ }^{1}$ Associate Professor, Department of General Surgery \\ ${ }^{2,3}$ Post Graduate, Department of General Surgery \\ *Corresponding Author \\ Dr Eppala Tejaswi \\ Post Graduate, Department of General Surgery
}

\begin{abstract}
Background: Ganglion cyst is the most common soft tissue tumour of the hand. 60-70 \% are present on dorsal aspect of wrist. They may affect any age group, however they are more common in 20s-40s. Although the pathogenesis is unclear, history of trauma is seen in 10\% of cases. These cysts are filled with fluids, and most often, they appear and disappear very quickly and majority of them do not require treatment unless the cyst is painful, alters function of the wrist or deformed appearance

Aims and Objectives: To study the size of ganglion cyst, symptoms at presentation, management done and outcomes.

Materials and Methods: A Retrospective analysis of all the cases of dorsal wrist ganglion presented to Surgical OPD over a period of 1 year, June 2020 to may 2021 at Maharajah's Institute of Medical Sciences, Vizianagaram and in them dorsal wrist ganglion cases were studied with respect to the size of the cyst, Symptoms at presentation, management done and outcomes.

Results: Total of 94 cases have been presented to Surgical OPD. Of it 60\% cases are of size greater $2 \mathrm{~cm}$. Symptoms: 14 cases presented with pain, 6 cases presented with tingling sensation others for cosmetic appearance and apprehension of tumour.

Management: wait \& watch(observation) for 36 cases of size less than 1cm; Immobilization (wrist brace or splint) for 8 cases which are arising from wrist joint; Aspiration \&steroid injection(triamcelone) for 35 cases; Surgical excision for 15 cases which were recurrences from previous management and painful cases.

Outcome: recurrence is the most common complication. Success by surgical excision was $86 \%$ and aspiration \&steroid injection was $75 \%$.

Conclusion: Recurrence after management was the most common complication of dorsal wrist ganglions. Surgical excision is the most successful form of treatment followed by aspiration \&steroid injection into the ganglion.

Keywords: Dorsal Wrist Ganglion, Excision, Aspiration and Injection.
\end{abstract}




\section{Introduction}

Ganglion cyst is the most common soft tissue tumor of the hand. 60-70\% are present on dorsal aspect of wrist. They may affect any age group; however, they are more common in 20s-40s.

Although the pathogenesis is unclear, history of trauma is seen in $10 \%$ of cases. These cysts are filled with fluids, and most often, they appear and disappear very quickly.

Majority of them do not require treatment unless the cyst is painful, alters function of the wrist or deformed appearance

They are the most common tumor like conditions in the hand and wrist which usually arise from a pedicle in tendon sheath or joint capsule and located over scapholunate ligament.

There are a number of treatment modalities for ganglion, such as observation, aspiration, intralesional steroid injection, sclerotherapy and surgical excision, but none of these modalities has been the standard or best treatment.

\section{Aims and Objectives}

To study the size, symptoms at presentation, management done and outcomes of ganglion cyst.

\section{Materials and Methods}

Study Type: A Retrospective analysis

Study Centre: Department of General surgery, Maharajah's Institute of Medical Sciences, Vizianagaram

Study Period: 2 years, June 2019 to May 2021.

Study subjects: All the cases of dorsal wrist ganglion

Dorsal wrist ganglion cases were studied with respect to the size of the cyst, Symptoms at presentation, management done and outcomes.

Diagnosis of ganglion was based on history and clinical examination. All patients were informed and explained about the lesion and their treatment plan.

In some patients, radiological investigations like $\mathrm{X}$-ray and ultrasonography were done to rule out other lesions.

\section{Inclusion Criteria}

1. Dorsal wrist ganglion of at least $1 \mathrm{~cm}$ in size

2. Patients older than 15 years (15-70 years)

3. Patients who are willing for follow-up.

\section{Exclusion Criteria}

1. Pediatric patients below the age of 15 years.

2. Patients refusing for investigations and treatment.

3. Those who are not willing to participate in the study.

4. Ganglion cysts present over other than dorsal wrist.

\section{Results}

Total of 94 cases have been presented to Surgical OPD.

Of it $60 \%$ cases are of size greater $2 \mathrm{~cm}$.

Symptoms: 14 cases presented with pain, 6 cases prsented with tingling sensation others for cosmetic appearance and apprehension of tumor.

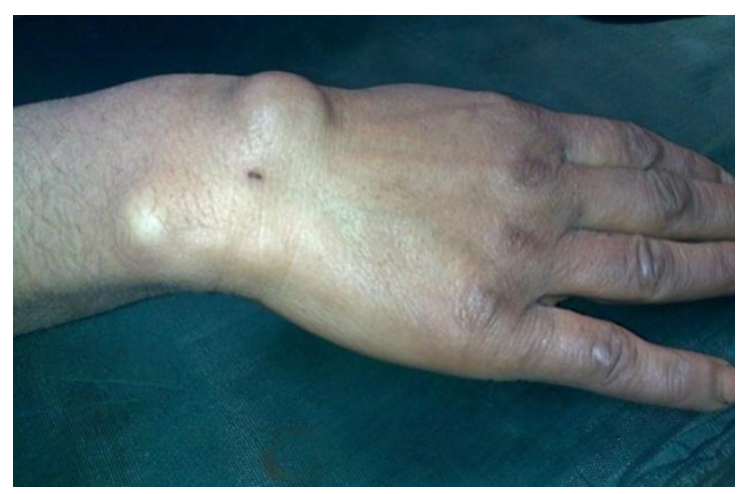

Photograph 1: Dorsal Wrist Ganglion

\section{AGE AND GENDER DISTRIBUTION}

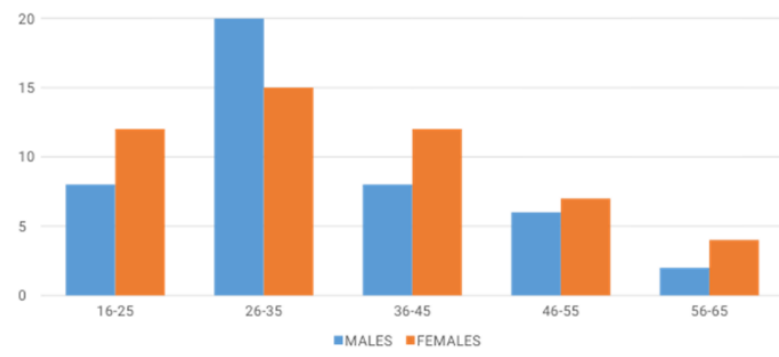

Figure 1: Age and Gender Distribution 
Age group of 26-35 years have highest incidence of dorsal wrist ganglion

Male to Female ratio 3:2

$60 \%$ of cases have dorsal wrist ganglion size > $2 \mathrm{~cm}$ in the study

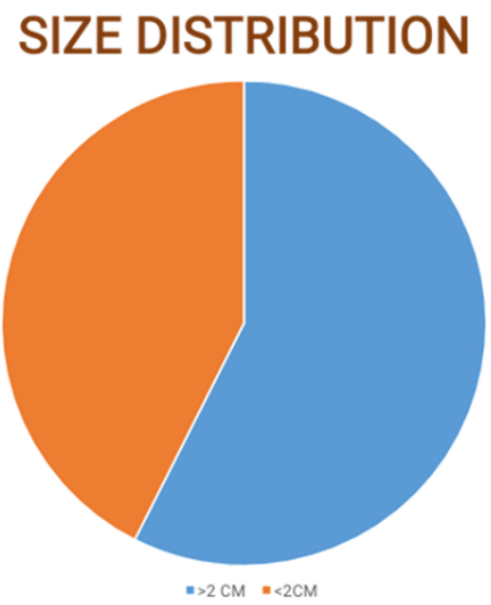

Figure 2: Size Distribution

Table1: Presenting Symptoms

\begin{tabular}{|l|l|c|}
\hline & \multicolumn{1}{|c|}{ SYMPTOMS } & CASES \\
\hline 1 & PAIN & 14 \\
\hline 2 & TINGLING SENSATION & 6 \\
\hline 3 & $\begin{array}{l}\text { OTHERS (COSMETIC, TUMOR } \\
\text { APPREHENSION) }\end{array}$ & 74 \\
\hline
\end{tabular}

\section{Management}

$>$ wait \& watch(observation) for 36 cases of size less than $1 \mathrm{~cm}$;

> Immobilization (wrist brace or splint) for 8 cases which are arising from wrist joint;

$>$ Aspiration \& steroid injection (triamcelone) for 35 cases;

$>$ Surgical excision for 15 cases which were recurrences from previous management and painful cases.

Table 2: Management

\begin{tabular}{|c|c|c|c|}
\hline & MANGEMINT & CAUSE & NO OF CASES \\
\hline 1 & WAIT \& WATCH(OBSERVATION) & $\begin{array}{c}\text { CYST LESSTHAN 1 CM } \\
\text { SIZE }\end{array}$ & 36 \\
\hline 2 & IMMOBILIZATION(WRISTBRACE) & $\begin{array}{c}\text { CYSTARISING FROM } \\
\text { JOINT CAPSULE }\end{array}$ & 8 \\
\hline 3 & $\begin{array}{c}\text { ASPIRATION \& STERIOD } \\
\text { INJECTION }\end{array}$ & $\begin{array}{c}\text { CYST GREATER THAN2 } \\
\text { CM SIZE }\end{array}$ & 35 \\
\hline 4 & $\begin{array}{c}\text { SURGICALEXCISION } \\
\text { RECURRENCES FROM } \\
\text { PREVIOUS }\end{array}$ & 15 \\
\hline & $\begin{array}{c}\text { MANAGEMENTAND } \\
\text { PAINFULCYST }\end{array}$ & \\
\hline
\end{tabular}

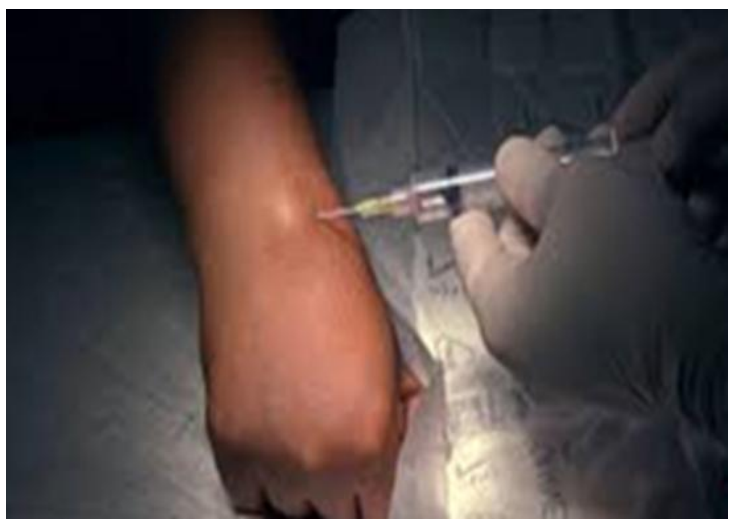

Photograph 2: Aspiration and Injection of steroid
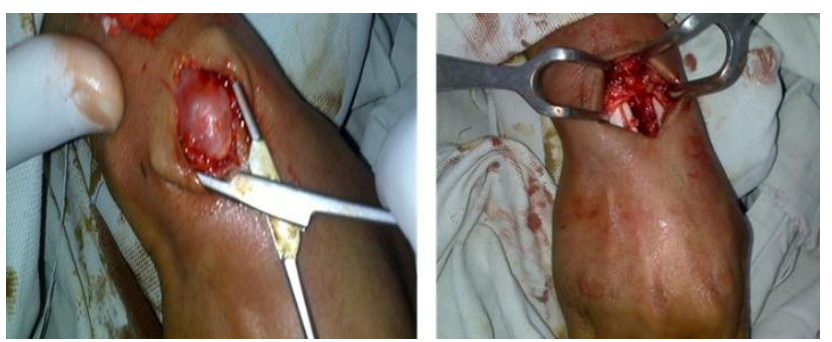

Photograph 3: Surgical Excision

\section{Outcome}

$\checkmark$ Recurrence is the most common complication.

$\checkmark$ Success by surgical excision was $86 \%$ and

$\checkmark$ aspiration \&steroid injection was 75\%

\section{Discussion}

Carpal ganglion cyst is the most common benign soft tissue tumor, including approximately 50$70 \%$ of the tumors of the hand and wrist area.

There are a number of treatment modalities for ganglion such as observation, aspiration, intralesional steroid injection, sclerotherapy and surgical excision, but none of these modalities has been the standard or best treatment.

The mean age of our patients at the time of presentation was 24.7 years.

Our study involved 94 patients with a male/female ratio of $3: 2$.

Wait \& watch (Observation) was done for all the ganglion cyst size less than $1 \mathrm{~cm}$ which spontaneously get resolved without intervention Immobilization with hand brace was done for the cysts arising joint capsule and the cyst spontaneously resolved 
Aspiration and injection Steroid (Triamcelone) was done for other cases which showed good results

Surgical excision was done for the recurrence cases of other treatment modalities and also for painful cysts.

Recurrence is the most common complication after management of dorsal wrist ganglion.

Surgical excision has the least incidence of recurrence of ganglion cyst.

\section{Conclusion}

Exact Pathogenesis of ganglion cyst is still unknown.

Recurrence after management was the most common complication of dorsal wrist ganglions.

Surgical excision is the most successful form of treatment followed by aspiration \& steroid injection into the ganglion.

\section{References}

1. Stephen A, Lyons A, Davis T. A prospective study of two conservative treatments for ganglia of the wrist. J Hand Surg Am. 1999;24:104-5. [PubMed] [Google Scholar]

2. Nield DV, Evans DM. Aspiration of ganglia. J Hand Surg Br. 1986; 11:264. [PubMed] [Google Scholar]

3. Gang RK, Makhlouf S. Treatment of ganglia by a thread technique. J Hand Surg Br. 1988;13:184-6. 